\title{
The Frequency of Skin Tumors and Infections in Patients with Autoimmune Diseases
}

\author{
Khalifa E. Sharquiee, ${ }^{1,2}$, Adil A. Noaimi1 ${ }^{1,2}$, Zina T. Burhan ${ }^{3}$ \\ ${ }^{1}$ Department of Dermatology, College of Medicine, University of Baghdad, Baghdad, Iraq \\ ${ }^{2}$ Iraqi and Arab Board for Dermatology and Venereology, Baghdad Teaching Hospital, Medical City, Baghdad, Iraq \\ ${ }^{3}$ Department of Dermatology, Baghdad Teaching Hospital, Medical City, Baghdad, Iraq \\ Email: "Ksharquie@ymail.com
}

Received 6 May 2016; accepted 8 August 2016; published 11 August 2016

Copyright (C) 2016 by authors and Scientific Research Publishing Inc.

This work is licensed under the Creative Commons Attribution International License (CC BY).

http://creativecommons.org/licenses/by/4.0/

(c) (i) Open Access

\section{Abstract}

Background: Autoimmune diseases are a vast array of organ-specific as well as systemic diseases, whose pathogenesis results from the activation of $B$ and $T$ lymphocytes reacting against antigens of the body's own tissues (defined as self). Objective: To record skin tumors and infections in all autoimmune diseases gathered together in a one pathological state, compared with renal transplant recipients and normal control. Patients and Methods: Four hundred patients with different autoimmune diseases were examined. Fifty patients with pemphigus (15 males, 35 females) are aged from $20-70(41.23 \pm 3.89)$ years. Fifty patients with systemic lupus erythematosus $(50$ females) are aged from $17-45(30.58 \pm 10.08)$ years. One hundred patients with vitiligo (59 males, 41 females) are aged from $9-71(42.89 \pm 5.28)$ years. One hundred patients with alopecia areata (42 males, 58 females) are aged from $7-52(38.67 \pm 9.52)$ years. One hundred patients with psoriasis (56 males, 44 females) are aged from $7-71(47.36 \pm 8.62)$ years were evaluated. One hundred twenty kidney transplant recipients' (101 males, 19 females) ages ranged from $14-70$ (45.43 \pm 4.63 ) years. All patients were examined thoroughly for any cutaneous manifestations and tumors and the findings were compared with the general population as a control group, which consisted of 500 healthy control individuals whose ages ranged from $20-71(44.53 \pm 11.48)$ years. This case series, descriptive, controlled study was performed in Baghdad Teaching Hospital from June 2014 to October 2015. Results: In renal transplant recipients, the findings were observed as follow herpetic infection in $30(25 \%)$, bacterial $12(10 \%)$ while fungal $24(20 \%)$ patients. These infections appeared early in the course of immunosuppression. While the tumors were noticed, the benign tumors were the commonest manifestations, which included viral warts in $45(37.5 \%)$ followed by actinic keratosis 15(12.5\%), seborrheic keratosis 14(11.6\%), sebaceous hyperplasia

"Corresponding author.

How to cite this paper: Sharquie, K.E., Noaimi, A.A. and Burhan, Z.T. (2016) The Frequency of Skin Tumors and Infections in Patients with Autoimmune Diseases. Journal of Cosmetics, Dermatological Sciences and Applications, 6, $140-147$.

http://dx.doi.org/10.4236/jcdsa.2016.64018 
13(10.8\%) and keratoacanthoma $1(0.8 \%)$. While the malignant tumors were basal cell carcinoma 4(3.3\%) followed by squamous cell carcinoma 3(2.5\%), and kaposi's sarcoma 4(3.3\%), Bowen's disease $\mathbf{1}(0.8 \%)$. These malignancy usually appeared late in the course of immunosuppression. In pemphigus, viral warts were observed in $4(8 \%)$ cases; fungal infection was seen in $4(8 \%)$ cases and bacterial infections in $2(4 \%)$ of cases and herpetic infection in only $1(2 \%)$ of case; no tumors were found in all patients. In vitiligo, viral warts were observed in $2(2 \%)$ cases, while seborrhic keratosis and sebaceous hyperplasia were observed in 1(1\%) case; herpetic and fungal infections were seen in $3(3 \%)$ of cases while bacterial infections were recorded in $2(2 \%)$ of cases but no tumors were found in all patients. In alopecia areata viral warts were observed in $9(9 \%)$ of cases, sebaceous hyperplasia in $1(1 \%)$ case, herpetic and bacterial in $3(3 \%)$ of cases and fungal in $4(4 \%)$ of cases; no tumors were found in all patients. In systemic lupus erythymatosus (SLE) viral warts were observed in $\mathbf{4}(8 \%)$ of cases, herpetic infection in $12(12 \%)$ of cases, fungal infection in $10(20 \%)$ of cases, bacterial infection in $3(3 \%)$ of cases and sebaceous hyperplasia in only $1(2 \%)$ of case, but no tumors were seen. In psoriasis, viral warts were observed in 14(14\%) of cases, herpetic infection in $10(10 \%)$ of cases, bacterial infection in $3(3 \%)$ of cases, fungal infection in $\mathbf{2}(2 \%)$ of cases, sebaceous hyperplasia in $2(2 \%)$ of cases and seborrhiec hyperkeratosis in $1(1 \%)$ case, while no tumors were demonstrated. In healthy control individuals, herpetic infection was present in $36(7.2 \%)$ and viral warts in 52(10.4\%) individuals, fungal infection in $29(5.8 \%)$ of individuals and regarding tumors solar keratosis was present in 24(4.8\%); basal cell carcinoma and squamous cell carcinoma were present in $2(0.4 \%)$ individuals of each. Conclusions: Patients with autoimmune diseases were protected against infections and tumors while kidney transplant recipients had no such protection although all these groups were on prolonged immunosuppression.

\section{Keywords}

Autoimmune Diseases, Kidney Transplant, Skin Infections, Skin Tumors

\section{Introduction}

Human autoimmune diseases (AD) occur frequently as affecting in aggregate more than $5 \%$ of the population worldwide, and impose significant burden of morbidity and mortality on the human population. Autoimmunity arises when immune responses mounted in the host are directed against self-components. AD are pathophysiological states that result from a loss of self-tolerance and the consequent immune destruction of host tissues. Autoimmunity is mediated by a variety of molecular and cellular events and responses. The development of an autoimmune disease is a very complex process in which recognition of self-antigens by lymphocytes is centrally involved in pathologic organ damage [1].

All these $\mathrm{AD}$ are common dermatological problems where there is immune reaction against normal tissue causing destruction of cells and resulting in disease state like pemphigus, systemic lupus erythematosus, vitiligo, alopecia areata. From clinical observations, we have noticed that patients with autoimmune diseases have lower frequency of skin malignancies and infections. This observation has been documented by many studies like patients with pemphigus, systemic lupus erythematous and vitiligo has protection against tumors [2]-[4]. While on reviewing literatures, we only found occasional case reports of infections and skin malignancies in these $\mathrm{AD}$ [5]-[14].

Kidney transplant patients are immunosuppressed because they are receiving steroids and cytotoxic drugs for long time, consequently skin infections and skin malignancies are increased among these patients like viral warts, bacterial and fungal infections. In addition, there was also increase in the skin malignancies like solar keratosis, squamous and basal cell carcinoma with Kaposi's sarcoma [15]-[18].

Among patients with kidney transplant, an entity has been described so called acquired epidermodysplasia verruciformis which has many features of the inherited type [19] [20].

So the aim of this study is to record skin tumors and infections in all autoimmune diseases gathered together in a one pathological state, and singly and to be compared with renal transplant recipients and normal control. 


\section{Patients and Methods}

A case, series, descriptive, controlled study was conducted during 1.5 year starting on June 2014 to October 2015.

Formal consent was taken from each patient after full explanation about the goal and nature of the present work. Also, ethical approval was taken from the Scientific Council of Dermatology and Venereology-Arab Board for Medical Specializations.

Four hundred patients with different autoimmune diseases were evaluated. Fifty patients with pemphigus (15 males, 35 females) their ages ranged from $20-70(41.23 \pm 3.89)$ years. Fifty patients with systemic lupus erythematosus (50 females) their ages ranged from $17-45$ years $(30.58 \pm 10.08)$ years. One hundred patients with vitiligo (59 males, 41 females) their ages ranged from $9-71(42.89 \pm 5.28)$ years. One hundred patients with alopecia areata (42 males, 58 females) their ages ranged from 7 - 52 (38.67 \pm 9.52$)$ years. One hundred patients with psoriasis (56 males, 44 females) their ages ranged from 7 - $71(47.36 \pm 8.62)$ years were seen in the Department of Dermatology, Baghdad Teaching Hospital, Baghdad, Iraq. One hundred twenty patients (101 males, 19 females) their ages ranged from $14-70(45.43 \pm 4.63)$ years with renal transplantation were seen in Baghdad and Al-Karama Teaching Hospitals, Baghdad, Iraq.

Five hundred apparently healthy individuals, their ages ranged from $20-71(44.53 \pm 11.48)$ years, had been seen. The patients and control were examined for dermatological tumors, infections and other skin lesions. Long history was taken from all patients, regarding: age, sex, duration of disease and detailed history for the treatment protocols. Physical examination was done for all patients and control including the covered and exposed areas looking for infections, tumors and other skin diseases. Each lesion was examined specifically regarding the type, size, color.

The treatment protocols for renal transplant patients were as follow:

1) Intravenous methylprednisolone succinate for the first 3 days:

Day $0250 \mathrm{mg}$. pre-op. $500 \mathrm{mg}$. I.OP. $250 \mathrm{mg}$. post-operative.

Day $1250 \mathrm{mg}$ twice daily. Day $2250 \mathrm{mg}$ twice daily. Followed by oral prednisolone $60 \mathrm{mg} /$ day tapered after one week to $20-30 \mathrm{mg} /$ day for two week then tapered slowly to a maintenance dose of $10 \mathrm{mg} / \mathrm{day}$ or $20 \mathrm{mg}$ every other day.

2) Azathioprine was given at doses ranging from $1-3 \mathrm{mg} / \mathrm{kg} /$ day according to the white blood cell count, doses were reduced whenever the WBC count fell below 4000/mm.

3) Cyclosporine, in combination with azathioprine was given orally starting with $8-10 \mathrm{mg} / \mathrm{kg} / \mathrm{day}$, decreased every two weeks by $2 \mathrm{mg} / \mathrm{kg} /$ day to a maintenance dose of $5 \mathrm{mg} / \mathrm{kg} /$ day.

4) Mycophenolate mofetal may be used with other immunosuppressant in a dose $1-2$ gm/day, the dosage should be gradually reduced in proportion to a favorable treatment response.

The treatment protocol for pemphigus includes the following:

1) Oral prednisolone given at a dose of $60-80 \mathrm{mg} /$ day tapered slowly after remission to a maintenance dose of equal to $10 \mathrm{mg} /$ day.

2) Azathioprine was given at doses ranging from $1-3 \mathrm{mg} / \mathrm{kg} /$ day, started with $150-200 \mathrm{mg} /$ day.

The treatment protocol for SLE includes the following:

1) Oral prednisolone given in a dose of $60 \mathrm{mg} /$ day then tapered slowly after remission to a maintenance dose of equal to $10 \mathrm{mg} / \mathrm{day}$.

2) Azathioprine was given in doses ranging from $1-3 \mathrm{mg} / \mathrm{kg} / \mathrm{day}$, started with $150 \mathrm{mg} / \mathrm{day}$.

While patients with other diseases like vitiligo, alopecia areata and psoriasis were having long history of using immunosuppressive drugs like topical and systemic corticosteroids with or without cytotoxic drug like methotrexate.

Statistical analysis of data was carried out using the statistical package of SPSS-20 (Statistical Packages for Social Sciences- version 20). Data were presented in simple measures of frequency, percentage, mean and standard deviation. Comparison between groups was done by using Chi Square, Fisher exact test, T-test and ANOVA test, $\mathrm{P}$-value $<0.05$ was considered as the level of significance.

\section{Results}

The frequency of skin diseases in renal transplant and $\mathrm{AD}$ patients includes the following:

\section{I-Benign tumors:}

1-Viral warts: In renal transplantation, viral warts were seen in $45(37.5 \%)$ cases, while viral warts was found in only 52(10.4\%) cases in a control group and there was statistically significant difference (P-value 
0.00000).

Most of the warty lesions were of the verruca vulgaris present as multiple and severe form mainly located on the face, neck, dorsum of the hands and feet, extensor of the forearm and legs and subungual verrucokeratotic lesions. These lesions appeared early in the course of immunosuppresion mostly in the first $10 \mathrm{yrs}$.

In pemphigus group, viral warts observed only in $3(6 \%)$ cases (Table 1 ). The warty lesions were single verrucous lesion and located on the dorsum of the hands in two patients and multiple verrocus lesions on the genital area in the other patient.

In SLE group, viral warts observed only in $4(8 \%)$ cases (Table 1 ). The warty lesions were of verruca vulgaris type, presented as a multiple lesions and located mainly on the hands and feet in 3 patients, and multiple verrocus lesions on the genital area in one patient.

In vitiligo group viral warts observed only in $2(2 \%)$ cases (Table 1$)$. The warty lesions were single verrucous lesion and located on the dorsum of the hand in one patient and multiple verrocus lesions on the knee of the other patient, both of the two patients had mild vitiligo.

In alopecia areata group viral warts observed only in $9(9 \%)$ cases (Table 1). Four of those patients had single verrucous lesion and located mainly on the dorsum of the hand, legs, sole, the warty lesions were multiple verrucous lesion in two patient located hands and multiple verrocus lesions on the knee in one patient. Those patients have localized disease. Two patient with alopecia universals developed verrucous lesions, the first patient has single verrucous lesion and located on the ventral surface of the index finger and the other has multiple verrocus lesions on the sole of the feet.

In psoriasis group viral warts observed only in $14(14 \%)$ cases (Table 1). Most of the warty lesions were of the verruca vulgaris present as multiple form mainly located on dorsum of the hands, palms, in one patient had multiple plane warts on the dorsum of the hands and ventral wrist.

2-Solar keratosis: In renal transplantation, solar keratosis observed in 15(12.5\%) cases, while 24(4.8\%) case were found in a control group, with statistically significant difference, $\mathrm{P}$ value $<0.0018$ (Table 3). Solar keratosis was seen in sun exposed areas like the face and the dorsa of both hands.

These were associated with solar lentigens and appeared at late onset of renal transplantation. No similar lesions found in all pemphigus, vitiligo, alopecia areata, SLE patients.

3-Seborrheic keratosis: In renal transplantation, seborrheic keratosis was seen in 14(11.6\%) cases, while $17(3.4 \%)$ patients were found in control group this findings was statistically significant when compared with control( $\mathrm{P}$ value $<0.0001$ ) (Table 3). These lesions were mainly present on the face, trunk and found in a severe form. In vitiligo seen in $1(1 \%)$ cases, no similar lesions were found in all pemphigus, alopecia areata, SLE, psoriasis patients.

4-Sebaceous hyperplasia: In renal transplant, appeared in $13(10.8 \%)$ cases. These lesions distributed mainly in the face and mainly found in patients received mycophenolate mofetil treatment. While $11(2.2 \%)$ cases observed in a control group. This was significantly difference when compared with control ( $\mathrm{P}$ value $<$ 0.00001) (Table 3). In psoriasis 2 cases were found. In vitiligo, alopecia areata, SLE patients, only one case was found.

5-Skin tags: In renal transplant, the lesions were present in 22(18.3\%) cases. while 57(11.4\%) cases in the control group (Table 1), in renal transplant these lesions were present mainly on the neck and the trunk and appeared in a severe form. In pemphigus $8(16 \%)$ cases were observed. In vitiligo $7(7 \%)$ cases were observed, alopecia areata $16(16 \%)$ cases were observed, SLE $7(14 \%)$ cases were found and in psoriasis $17(17 \%)$ cases were found (Table 1).

6-keratoacanthoma: In renal transplant only one $(0.8 \%)$ case was present, while $2(0.4)$ cases were observed in control group, (Table 1). No similar lesion was present in pemphigus, vitiligo, alopecia areata, SLE, psoriasis.

\section{II-Malignant tumors:}

1-Basal cell carcinoma: In renal transplantation 4(3.3\%)cases were present (Table 1), these were present in male patients and in sun exposed parts, the face and dorsum of the hands, this increased with increased duration of immunosuppression, while $2(0.4 \%)$ cases were observed in the control group. In pemphigus, vitiligo, alopecia areata, SLE, psoriasis no basal cell carcinoma was detected.

2-Squamous cell carcinoma: In renal transplant, there were 3(2.5\%) cases (Table 1), these lesions were noted in male patients and on sun exposed parts, the face and dorsum of the hands, and associated mainly with solar keratosis, while $2(0.4 \%)$ cases were observed in a control group. In AD no similar lesions were present.

3-Kaposi's sarcoma: In renal transplant patients, 4(3.3\%) cases were found, while was absent in control group, (Table 1). In two cases the lesions found in the buccal mucosa (1 female, 1 male), and in one patient had 
lesion on the hard palate, in preauricular area and lower extremities and in one young male patient had lesion in the upper and lower extremities. The lesions appeared at an early onset after renal transplantation. No similar lesions were detected in $\mathrm{AD}$.

4-Bowen's disease: In renal transplant, the lesion was present in only one $(0.8 \%)$ case on the dorsum of the right hand. No such lesion present on control and on $\mathrm{AD}$ group.

\section{III-Infectious lesions:}

1-Herpetic infections: Were seen in 30(25\%) cases of transplant patients. Herpes zoster were present in $14(11.6 \%)$ cases, while herpes simplex infection found in $10(8.3 \%)$ of cases. Chicken pox was found in one $(0.8 \%)$ case. These infections were present mainly in the first years following transplantation, while in pemphigus, only one case was detected, in vitiligo, alopecia areata 3(3\%) had herpes simplex in each group, in SLE herpetic infections were seen in $12(24 \%)$ cases, herpes zoster were present in 4(8\%) cases, while herpes simplex infection found in $8(16 \%)$ of cases and in psoriasis herpes simplex were seen in $10(10 \%)$ cases. In control group there were 36(7.2\%) cases most of them had herpes simplex infection (Table 2).

2-Bacterial infections: In renal transplant patients were seen in 12(10\%) cases (Table 2). These lesions include 9 cases of folliculitis and one impetigo, one abscess and one with tuberculosis. While in pemphigus patients only $2(4 \%)$ cases were detected one case with impetigo and one with multiple boils, in SLE bacterial infections were seen in $3(6 \%)$ cases, these lesions include one case of multiple boils, one abscess and one with distal dactylitis, in vitiligo only $2(2 \%)$ cases were detected one case with impetigo and one with folliculitis, in alopecia areata $3(3 \%)$ cases were detected, 2 cases with folliculitis and one with impetigo, in psoriasis bacterial infections were seen in 3(6\%)cases, these lesions include one case with multiple boils, one abscess and one with cellulitis, and in control group bacterial infections were seen in 11(2.2\%) of cases, most of the lesions were in the form of impetigo and folliculitis.

3-Fungal infections: In renal transplant patients there were 24(20\%) cases (Table 2). These lesions were mainly tinea versicolor, tinea cruris and tinea pedis. While in pemphigus patients fungal infections was present in $4(8 \%)$ cases which included one case with tinea pedis, one case with tinea cruris, one case with pityriasis versicolor and one case with Candida. In SLE fungal infections was present in 10(20\%) cases, most of the lesions were in the form of pityriasis versicolor and Candida, in vitiligo 3(3\%) cases were detected including 2 cases with tinea pedis and one case with Candida, these cases had mild vitiligo in alopecia areata 4(4\%) were detected including two cases with tinea pedis and one case with pityriasis versicolor, one case with Candida cases, these cases had localized alopecia areata, in psoriasis $12(12 \%)$ of cases which included 5 cases with tinea pedis, 2 cases with tinea cruris and 5cases with Candida of oral cavity and interdigital spaces. In control group 29(5.8\%) cases were detected, most of cases were in the form of pityriasis versicolor, tinea pedis, Candida in the interdigital spaces and sub-mammary region.

When all $\mathrm{AD}$ were considered together as one disease and compared with kidney transplant and control groups, the results were shown in (Table 3, Table 4).

\section{Discussion}

Autoimmune diseases are pathophysiological states that result from a loss of self-tolerance and the consequent

Table 1. The distribution of benign and malignant skin tumors in renal transplant patients, AD and control.

\begin{tabular}{cccccccc} 
& $\begin{array}{c}\text { Renal transplant } \\
\text { NO(\%) }\end{array}$ & $\begin{array}{c}\text { SLE } \\
\text { NO(\%) }\end{array}$ & $\begin{array}{c}\text { Pemphigus } \\
\text { NO(\%) }\end{array}$ & $\begin{array}{c}\text { Vitiligo } \\
\text { NO(\%) }\end{array}$ & $\begin{array}{c}\text { Alopecia areata } \\
\text { NO(\%) }\end{array}$ & $\begin{array}{c}\text { Psoriasis } \\
\text { NO(\%) }\end{array}$ & $\begin{array}{c}\text { Control } \\
\text { NO(\%) }\end{array}$ \\
\hline Viral warts & $45(37.5)$ & $4(8)$ & $3(6)$ & $2(2)$ & $9(9)$ & $14(14)$ & $52(10.4)$ \\
Solar.Keratosis & $15(12.5)$ & $0(0)$ & $0(0)$ & $0(0)$ & $0(0)$ & $0(0)$ & $0(0)$ \\
Seborrheic keratosis & $14(11.4)$ & $0(0)$ & $1(2)$ & $1(1)$ & $0(0)$ & $1(1)$ & $17(3.4)$ \\
Sebaceous hyperplasia & $13(10.8)$ & $1(2)$ & $1(2)$ & $1(1)$ & $2(2)$ & $2(2)$ & $2(0.4)$ \\
Skin tags & $22(18.3)$ & $7(14)$ & $8(16)$ & $7(7)$ & $16(16)$ & $17(17)$ & $57(11.4)$ \\
Keratoacanthoma & $1(0.8)$ & $0(0)$ & $0(0)$ & $0(0)$ & $0(0)$ & $0(0)$ & $2(0.4)$ \\
BCC & $4(3.3)$ & $0(0)$ & $0(0)$ & $0(0)$ & $0(0)$ & $0(0)$ & $2(0.4)$ \\
SCC & $3(2.5)$ & $0(0)$ & $0(0)$ & $0(0)$ & $0(0)$ & $0(0)$ & $2(0.4)$ \\
Kaposi's sarcoma & $4(3.3)$ & $0(0)$ & $0(0)$ & $0(0)$ & $0(0)$ & $0(0)$ & $0(0)$ \\
Bowen's disease & $1(0.8)$ & $0(0)$ & $0(0)$ & $0(0)$ & $0(0)$ & $0(0)$ & $0(0)$ \\
\hline
\end{tabular}


Table 2. The distribution of skin infections in renal transplant patients, AD and control.

\begin{tabular}{cccccccc}
\hline & $\begin{array}{c}\text { Renal Transplant } \\
\text { NO(\%) }\end{array}$ & $\begin{array}{c}\text { SLE } \\
\text { NO(\%) }\end{array}$ & $\begin{array}{c}\text { Pemphigus } \\
\text { NO(\%) }\end{array}$ & $\begin{array}{c}\text { Vitiligo } \\
\text { NO(\%) }\end{array}$ & $\begin{array}{c}\text { Alopecia } \\
\text { areata NO(\%) }\end{array}$ & $\begin{array}{c}\text { Psoriasis } \\
\text { NO(\%) }\end{array}$ & $\begin{array}{c}\text { Control } \\
\text { NO(\%) }\end{array}$ \\
\hline Herpetic infections & $30(25)$ & $12(24)$ & $1(2)$ & $3(3)$ & $3(3)$ & $10(10)$ & $36(7.2)$ \\
Bacterial infections & $12(10)$ & $2(4)$ & $1(2)$ & $2(2)$ & $3(3)$ & $3(3)$ & $11(2.2)$ \\
Fungal infections & $24(20)$ & $10(20)$ & $4(8)$ & $3(3)$ & $4(4)$ & $12(12)$ & $29(5.8)$ \\
\hline
\end{tabular}

Table 3. The distribution of benign and malignant skin tumors in renal transplant patients, AD and control.

\begin{tabular}{cccccc}
\hline & $\begin{array}{c}\text { Renal transplant } \\
(120) \mathrm{NO}(\%)\end{array}$ & P value & $\begin{array}{c}\text { Autoimmune diseases } \\
(400) \mathrm{NO}(\%)\end{array}$ & $\begin{array}{c}\text { P value } \\
\text { Control(500) } \\
\text { NO(\%) }\end{array}$ \\
\hline Viral warts & $45(37.5)$ & $0.0000^{*}$ & $32(8)$ & 0.218 & $52(10.4)$ \\
Solar.Keratosis & $15(12.5)$ & $0.0018^{*}$ & $0(0)$ & $0.00002^{*}$ & $24(4.8)$ \\
Seborrheic Keratosis & $14(11.4)$ & $0.0001^{*}$ & $3(0.75)$ & $0.0141^{*}$ & $17(3.4)$ \\
Sebaceous Hyperplasia & $13(10.8)$ & $0.00001^{*}$ & $7(1.75)$ & 0.8106 & $11(2.2)$ \\
Skin Tags & $22(18.3)$ & $0.04^{*}$ & $55(13.7)$ & 0.2885 & $57(11.4)$ \\
Keratacanthoma & $1(0.8)$ & 0.4761 & $0(0)$ & 0.3083 & $2(0.4)$ \\
Basal cell carcinoma & $4(3.3)$ & $0.0145^{*}$ & $0(0)$ & 0.3083 & $2(0.4)$ \\
Squamous cell carcinoma & $3(2.5)$ & $0.05^{*}$ & $0(0)$ & 0.3083 & $2(0.4)$ \\
Kaposi's sarcoma & $4(3.3)$ & $0.0013^{*}$ & $0(0)$ & - & - \\
Bowe's disease & $1(0.8)$ & 0.1935 & $0(0)$ & $0(0)$ \\
\hline
\end{tabular}

*significant difference when $\mathrm{P}$ value was equal or less than 0.05 level.

Table 4. The distribution of skin infection in renal transplant patients, AD and control.

\begin{tabular}{ccc|ccc}
\hline & $\begin{array}{c}\text { Renal Transplant } \\
(120) \mathrm{NO}(\%)\end{array}$ & P value & $\begin{array}{c}\text { Autoimmune diseases } \\
(400) \mathrm{NO}(\%)\end{array}$ & $\begin{array}{c}\text { P value } \\
\text { Control(500) } \\
\text { NO(\%) }\end{array}$ \\
\hline Herpetic infections & $30(25)$ & $0.00000^{*}$ & $29(7.25)$ & 0.9770 & $36(7.2)$ \\
Bacterial infections & $12(10)$ & $0.00004^{*}$ & $11(2.75)$ & 0.5954 & $11(2.2)$ \\
Fungal infections & $24(20)$ & $0.0000^{*}$ & $33(8.25)$ & 0.1492 & $29(5.8)$ \\
\hline
\end{tabular}

${ }^{*}$ significant difference when $\mathrm{P}$ value was equal or less than 0.05 level.

immune destruction of host tissues [1]. All these AD are common dermatological problems where there is immune reaction against normal tissue causing destruction of cells and resulting in disease state like pemphigus vulgaris, SLE, vitiligo, alopecia areata.

Sharquie et al. had conducted and published many studies that found AD like as pemphigus, SLE and vitiligo had protection against skin tumors and infections although these diseases were treated by immunosuppressive drugs as prolonged course of therapy [2]-[4]. These interesting findings are supported when these results are compared with patients with kidney transplant who had high frequency of skin tumors and infections. And to support more this new hypothesis, the present work was conducted where many AD under prolonged drug induced immunosuppression, are considered together in order to study the frequency of skin tumors and infections and to be compared with patients with kidney transplant. In the present work we confirmed similar findings as there was increase in infections like viral warts, herpetic, bacterial, fungal infections and tumors like BCC, SCC in kidney transplant patients.

While all cases of pemphigus vulgaris, vitiligo, alopecia areata showed no increase in the frequency of these infections, compared to kidney transplant patients and healthy control and most infections were seen in cases of mild vitiligo and localized alopecia areata. Also, no skin malignancies including solar keratosis, BCC, SCC and Kaposi's sarcoma were seen in patients with $\mathrm{AD}$ while they were in high frequency in patients with kidney transplant. But some $\mathrm{AD}$ are more protective than the others in decreased order like pemphigus, vitiligo, alopecia areata, SLE as had been seen in the present study. 


\section{Conclusion}

All autoimmune diseases including pemphigus vulgaris, vitiligo, alopecia areata are protective against skin tumors and infections although some results are comparable between $\mathrm{AD}$ and the control group but still significant as patients with $\mathrm{AD}$ have already received immunosuppressive drugs for a long time.

\section{Funding}

This study was an independent study and not funded by any drug companies.

\section{References}

[1] Ray, S., Sonthalia, N., Kundu, S. and Gungaly, S. (2012) Autoimmune Disorders: An Overview of Molecular and Cellular Basis in Today's Perspective. Journal of Clinical and Cellular Immunology, S10, 3. http://dx.doi.org/10.4172/2155-9899.S10:003

[2] Sharquie, K.E., Noaimi, A.A. and Al-Jobori, A.A. (2014) Skin Tumors and Infections in Kidney Transplant Recipients versus Patients with Pemphigus Vulgaris. International Journal of Dermatology, 53, 288-293. http://dx.doi.org/10.1111/j.1365-4632.2012.05708.x

[3] Sharquie, K.E., Noaimi, A.A. and Al-Jobori, A.A. (2011) Skin Tumors and Infections in Kidney Transplant Recipients versus Patients with Pemphigus and Systemic lupus Erthymatosus. A Thesis Submitted to the Scientific Council of Dermatology and Venereology_-Iraqi Board for Medical Specializations in Dermatology and Venereology.

[4] Sharquie, K.E., Noaimi, A.A. and Murtada, S.J. (2016) The Frequency of Benign and Malignant Skin Tumors among Patients with Different Severity of Vitiligo Compared with the Skin Tumors in Healthy Control. A Thesis Submitted to the Scientific Council of Dermatology and Venereology_-Iraqi Board for Medical Specializations in Dermatology and Venereology.

[5] Avalos-Peralta, P., Herrera, A., Ríos-Martín, J.J., Pérez-Bernal, A.M. and Moreno Ramírez, D. (2006) Localized Kaposi's Sarcoma in a Patient with Pemphigus Vulgaris. Journal of the European Academy of Dermatology and Venereology, 20, 79-83. http://dx.doi.org/10.1111/j.1468-3083.2005.01348.x

[6] Mahomed, Y., Mandel, M.A., Cramer, S.F. and Michel, B. (1980) Squamous Cell Carcinoma Arising in Pemphigus Vulgaris during Immunosuppressive Therapy. Cancer, 46, 1374-1377. http://dx.doi.org/10.1002/1097-0142(19800915)46:6<1374::AID-CNCR2820460614>3.0.CO;2-1

[7] Pagani, W.A., Rimondi, A.P., Chiacchiarini, A. and Lorenzi, G. (1990) Basal Cell Carcinoma Arising in Pemphigus Vulgaris of the Lower Eyelid. Journal of Dermatologic Surgery \& Oncology, 16, 1152-1154. http://dx.doi.org/10.1111/j.1524-4725.1990.tb00028.x

[8] Kyriakis, K., Stavropoulos, P., Hatziolou, E., Dellidis, G., Varelzidis, A. and Tosca, A. (1991) Coexistence of Pemphigus Vulgaris, Malignant Melanoma and Low-Grade Lymphoma. Dermatologica, 183, 49-52. http://dx.doi.org/10.1159/000247632

[9] Pamela, P., Lee, W., Lee, T.-L., Ho, M.H.-K., Wong, W.H.S. and Lau, Y.-L. (2006) Herpes Zoster in Juvenile-Onset Systemic Lupus Erythematosus. Pediatric Infectious Diseases Journal, 25, 728-732. http://dx.doi.org/10.1097/01.inf.0000226841.03751.1f

[10] Johansson, E., Pyrhönen, S. and Rostila, T. (1977) Warts and Wart Virus Antibodies in Patients with Systemic Lupus Erythematosus. British Medical Journal, 1, 74-76. http://dx.doi.org/10.1136/bmj.1.6053.74

[11] Greenfield, D.I., Trinh, P., Fulenwider, A. and Barth, W.F. (1986) Kaposi's Sarcoma in a Patient with SLE. The Journal of Rheumatology, 13, 637-640.

[12] Teulings, H.E., Overcamp, M., Ceylan, E., Nieuweboer-Krobotova, L., Bos, J.D., Nijsten, T., et al. (2013) Decreased Risk of Melanoma and Non Melanoma Skin Cancer in Patients with Vitiligo. British Journal of Dermatology, 168, 162-171. http://dx.doi.org/10.1111/bjd.12111

[13] Hexsel, C.L., Eide, M.J., Johson, C.C., Krajenta, R., Jacobsen, G., Hamzavi, I. and Lim, H.V.V. (2009) Incidence of Non-Melanoma Skin Cancer in Acohort of Patients with Vitiligo. Journal of the American Academy of Dermatology, 60, 929-933. http://dx.doi.org/10.1016/j.jaad.2008.09.033

[14] Schallreuter, K.U., Tobin, D.J. and Panske, A. (2002) Decreased Photodamage and Low Incidence of Non-Melanoma Skin Cancer in 136 Sun-Exposed Caucasian Patients with Vitiligo. Dermatology, 204, 194-201. http://dx.doi.org/10.1159/000057881

[15] Annelies, A., Peter, A. and Martina, B. (2002) Skin Changes and Tumors after Renal Transplantation. Nephron, 91, 188-196. http://dx.doi.org/10.1159/000058391

[16] Jean, K., Lina, A., Sylvie, E. and Alain, G. (2003) Basal Cell Carcinoma Developing in Solid Organ Transplant Reci- 
pient. Transplantation Proceedings, 139, 1-8.

[17] Harden, P., Freyer, A., Reece, S. and Ramsay, H. (2001) Annual Incidence of Non Melanoma Skin Cancer in Renal Transplant Recipient. Transplantation Proceedings, 33, 1302-1304.

[18] Zeier, M., Hartschuch, W., Weisel, M., Lehnert, T. and Ritz, E. (2002) Malignancy after Renal Transplantation. American Journal of Kidney Diseases, 39, P1- P5. http://dx.doi.org/10.1053/ajkd.2002.29926

[19] Sharquie, K.E., Al-Mashhadani, S.A., Noaimi, A.A. and Abbas, M.Y. (2011) Acquired Epidermodysplasia Verruciformis in Kidney Transplant Patients. Journal of the Saudi Society of Dermatology and Dermatological Surgery, 15, 53-56. http://dx.doi.org/10.1016/j.jssdds.2011.04.006

[20] Sharquie, K.E., Noaimi, A.A. and Al-Jobori, A.A. (2012) Re-Evaluation of Acquired Epidermodysplasia Verruciformis in Kidney Transplant Recipients. JCDSA, 2, 174-178. http://dx.doi.org/10.4236/jcdsa.2012.23033

\section{Submit or recommend next manuscript to SCIRP and we will provide best service for you:}

Accepting pre-submission inquiries through Email, Facebook, LinkedIn, Twitter, etc.

A wide selection of journals (inclusive of 9 subjects, more than 200 journals)

Providing 24-hour high-quality service

User-friendly online submission system

Fair and swift peer-review system

Efficient typesetting and proofreading procedure

Display of the result of downloads and visits, as well as the number of cited articles

Maximum dissemination of your research work

Submit your manuscript at: http://papersubmission.scirp.org/ 